\title{
The Greek Key: Getting Acquainted in Athens
}

\section{Hunter Augeri \\ Eirene Efstathiou \\ Maria Michou \\ Jan Motyka Sanders}

Arcadia University Center for Hellenic, Mediterranean

and Balkan Studies, Athens

\section{Introduction}

Greece conjures up images of idyllic island landscapes, turquoise seas and venerable mythic deeds set among majestic, if now slightly ruinous, monuments. These notions are, moreover, often associated with a history and language that are ancient. Indeed, the Parthenon still perches on the Akropolis in downtown Athens. This naïve notion of historical and cultural continuity, however, disguises and, in some cases, erases some of the factors that have made Greece and its capital city, Athens, what they are today. These factors include a hard won ethnic identity strongly associated with membership in the Greek Orthodox Church and a language that has been spoken for 34 centuries. For 400 years, from 1453 to the 1820 , Greece was ruled by the Ottomans based in Istanbul, formerly Greek Constantinople, a city the Greeks to this day call Constantinople. The Church and a common language kept Greekness alive during this occupation and it was only with independence from the Ottoman Empire in 1830 that Greece became a nation state. The Balkan Wars of the early $20^{\text {th }}$ century, WWI, and the first internationally sanctioned exchange of populations in 1923 between Greece and Turkey added to the geographical mass of Greece and changed somewhat the makeup of Greeks. More recently, Greece's lengthy and porous coastline has absorbed a significant number of refugees and immigrants who now make up at least $15 \%$ of the inhabitants of Greece.

Tourist posters and national sentiment aside, today the Hellenic Republic is a country that is as much European as it is Mediterranean, Levantine and Balkan. In other words, it defies categorization. This multiple identity gives us a remarkable tool when working with study abroad students who find their 
way to Greece because, no matter what expectations or assumptions a student may travel with, they are rarely met once the student reaches Athens. In fact, these mis-expectations are perfectly situated to act as one half of a double exposure: what do the students expect to see - if they can articulate it at all and what do they actually encounter? The following text uses The Greek Key: Experiencing Athens as a Cultural Landscape, a required course at the Arcadia University College of Global Studies' program in Athens, as an arena in which to address this question and suggest pedagogical strategies for helping students reconcile the expectations about Athens and Athens' realities.

\section{The Problem}

Gnothi seauton ( $\gamma v \tilde{\omega} \theta \mathrm{u}$ ocavtóv), "know yourself" or, perhaps more accurately, "get acquainted with yourself," is a much-quoted aphorism associated with Apollo, the ancient Greek god of reason, harmony, music and light. When asked to anticipate and articulate their expectations, the responses of study abroad students in Athens are eerily similar to this dictum in their expression of an intention to seek out challenge and to move outside a regular comfort zone. The first few weeks of an international experience are invariably challenging for all concerned and it is too easy for students to think they are learning about Greece when, in actual fact, they are only scratching the surface. While the unfamiliar landscape of Athens, both physically and culturally, contains the lure of an unexplored territory, certain tools and strategies are needed to help the student learners read and attempt to understand their experiences of the new.

Inspired in part by Apollo and frustrated in equal measure by the difficulties the students encounter in maintaining their attempts to engage with Greece, in-country staff at the Arcadia University College of Global Studies Athens center created The Greek Key: Experiencing Athens as a Cultural Landscape to assist student learners in Athens to get acquainted with themselves by using the city of Athens, and Greece itself, to achieve this goal. Using the city as a landscape on which a particular culture is writing, remembering and re-inventing itself, the Greek Key attempts to accommodate experiential learning not only in the casual transactions of the everyday, but also in the challenge of reading culture on the actual space and construction of the city. Not only do the student learners get below the surface of contemporary Athens, while doing this they also develop the ability to 
recognize their assumptions, fear and even stereotypes and overcome them or put them aside.

\section{Athens as the Classroom}

Athens, with its bustling traffic, limited parks and the overwhelmingly solid béton armé structures facing onto seemingly chaotic street patterns, projects at first the image of an urban world homogeneously unreadable and difficult to penetrate. The internationally exported landmark destinations of Athens - the Akropolis and other built traces of its classical past - often stand out inexplicably distanced from their immediate contemporary surroundings. After visiting the Parthenon and the highly acclaimed new Akropolis Museum, the newcomer will find herself wandering between the tourist-oriented Ottoman neighborhood of Plaka and the adjacent historical market district of Monastiraki, to eventually be greeted by the post-industrial entertainment areas of Kerameikos and Psyrri. Here, the winding streets and low-rise buildings appear as remains of a city model from a previous time, readily transformed to cater for the stereotypical image of a Mediterranean paradise. The setting, however, fuses into a much less legible relief once the sojourner places herself beyond the limits of a simple trip to the city of Athens.

A village until the 1830 , the capital of the Hellenic Republic bears on its surface the marks not only of the country's modernization and consequent development into a contemporary European state, but also the efforts of a diverse people to shape a homeland where for the first time in Greece's lengthy history they would share a common religion and language. Built almost from scratch, Athens unfolds on its streets the aspirations both of her imported appropriators - city planners, architects educated abroad, wealthy expatriates who sponsored the construction of the first university buildings, kings and queens - and the anonymous masses who arrived in Athens longing simply for a better future, either as refugees from Asia Minor in the 1920's, or as internal migrants from every part of the Greek countryside later in the century. Much of the downtown's present building stock originates from the defining postwar decades of the 1960 s and ' 70 s when a system of exchange between small landowners and local contractors allowed for the hasty construction of entire residential areas essentially without real capital, areas that now define the Athenian landscape as a utilitarian urban jungle. Punctuated by older Byzantine churches, widely used public squares, the few grand neoclassical 
structures of the old University and Parliament, and more recent but less magnificent blocks accommodating other public institutional bodies, the Athenian urbanity constitutes a unique amalgam between intentional planning and development out of necessity and private will.

Similarly bound to its recent socioeconomic and political fluctuations, Athenian culture also negotiates a place for itself. Populated by older generations whose birthplaces are far from Athens, ambitious career followers and youth in search of new opportunities or markets and a vibrant nightlife, and first and second generation economic refugees of mixed ethic origins and religions, the Greek capital is a fusing pot that outlines a sense of belonging as multi-faceted as it is fragile. Athenian culture appears to constantly re-invent its own unique version of a deeply embedded Balkan cosmopolitanism, oscillating between capitalist lifestyle models and the omnipresent influences of Greece's Ottoman past. Orientated toward the center of dominant Western cultural production but physically located at Europe's periphery, Athens' social reality refuses to be reduced to a seamless narration.

The map, a totalizing stage on which elements of diverse origin are brought together to form a tableau of a "state" of geographical knowledge, pushes away into its prehistory or into its posterity, as if into the wings, the operations of which it is the result or the necessary condition. It remains alone on the stage. The tour describers have disappeared. (de Certeau,1998, p. 121)

The Greek Key attempts to familiarize learners with Athens' dynamic socio-cultural environment, all under the veil of historical symbolism and internal mutiny. Structured around scheduled group walks in selected neighborhoods of Athens, as well as individual explorations of proposed venues and activities, the Greek Key aims at engaging learners with local customs via first-hand exploration and observation. In re-visiting Baudelaire's flâneur (Benjamin, 1999, p. 416), a non-participating but highly perceptive strolling observer of the built environment, focus is placed on the ways in which contemporary living has shaped our way of inhabiting and experiencing our surroundings. The flâneur can be used as a means to ignore and transgress the seductive images of guidebooks and television commercials, the mass-mediated image of the city, and step beyond the rushed experience of habitual walking or the totalizing flatness of the city map. Returning to plain sight as the prominent cognitive sense towards knowing 
space, and also to expand onto the rest of the senses, smell, sound, tactility, and even taste (Pallasmaa, 2005, p. 21), students are challenged to observe what is there, the immediately real: to lift their eyes beyond the street level, describe the ways sound is alternating as they move through the city, read on the actual building matter traces of time, use, and abuse.

Here, the facilitator acts as an intermediary between the city and learners, more as a revealer of the unfamiliar than as a performer of a prescribed sightseeing tour. Stepping out of the traditional role of the lecturer, the facilitator is not there to simply recite the history of the neighborhood and point out details. Rather, combining the pedagogy of architecture, archaeology, art and sociology, the Greek Key facilitator must conduct herself in a manner that more closely resembles the warm grip of a friend's guidance.

In anticipation of every walk, learners are assigned readings, some particularly related to their destination; others from contemporary theory in reference to the four running themes of the Greek Key: social history, spatial narration, walking as mapping, memory. While most of the readings are not specific to the Athenian metropolis, each offers a glimpse of a subjective reading of it as an urban environment. Some are poems telling of an ancient Greek journey (Cavafy, 2006), while others are fictional accounts of a multifaceted metropolis (Calvino, 1997).

The guided walks take place in selected districts of central Athens, chosen as instances characteristic or exceptional to the Athenian urban conglomerate. Destinations range from the Omonoia Square, the commercial center of modern downtown Athens, and the Central Market, where learners are faced with the extrovert manner of traditional trade and the raw experience of fresh meat and fish, to the densely populated neighborhood of Kypseli with its multi-national ethnic populations of economic refugees mixing with old Athenian residents. Other walks include the lower-middle class settlement Akadimia Platonos, an area adjacent to the archaeological remains of Plato's Academy, or the Asia Minor refugee suburb of Kaisariani where students witness bullet scars on the faces of stately homes from WWII and the memorial at the shooting range where the Nazi occupation forces executed members of the local Communist resistance. In the heterotopian (Foucault, 24) illegal settlement of Anafiotika at the foot of the Akropolis Hill, the group wanders through the labyrinthine streets of an otherwise typical island village. In the ambiguously alternative area of Exarcheia, home to anarchist groups, students focus on aspects of state authority and private ownership and how these affect notions of collective belonging, evident in the activism of residents 
to create public green spaces in unkempt plots owned by large businesses or the state.

To become acquainted with the sites, learners are asked to notice and compare Athenian street patterns and building types and their uses with patterns and types familiar from home. They also are to read and comment on posters and graffiti in order to unravel the political identity of local inhabitants, discover and name the most prominent activities that take place in the area, and discuss the effects on the tactile material of public space. Informed about the socio-historical background of each place, the evolution of planning legislation and dominant architectural trends, learners are able to comprehend the common necessities, historical fractures and enveloping legal framework under which the city has been formed. Understanding Athens as a dynamic ever-changing metropolis, learners become familiar with the ways contemporary needs and local idiosyncrasies employ, adapt, and reappropriate existing structures or unspoken boundaries, either directed by organized government projects or anonymously - often spontaneously or against official law. Finally, toward the end of each walk the class pauses to discuss the theoretical readings assigned for the walk in a public square or improvised sitting spot and reflect on their understanding of the texts' proposals in relation to the urban structure, identity, and atmosphere of the specific destination. At this point, the class also is asked to articulate personal thoughts on the experience.

The readings for the Greek Key draw from the extensive genre of theoretical writings about the city. In most cases they are not site specific to Athens and as such, they are meant to act as models rather than literal explanations for interacting with a city. As well, they are intended to be impetus for reflective writing about their experiences of the city. The Greek Key begins with an epigram from Walter Benjamin's Arcades Project (1999):

The street conducts the flâneur into a vanished time. For him every street is precipitous. It leads downwards -- if not to mythical mothers, then into a past that can be all the more spellbinding because it is not his own, not private. Nevertheless, it always remains the time of a childhood. But why that of a life he has lived? In the asphalt over which he passes, his steps awaken a surprising resonance. The gaslight that streams down throws an equivocal light on this double ground. (p. 416) 
In many ways, Benjamin's epigram encapsulates the learning objectives of the readings. It speaks about the learners' subjective position in relationship to what they are looking at and it encourages this looking to be an excavation of the possible histories embedded in the city itself as well as the history, expectations, and memories that the students themselves bring to the investigation. Benjamin's epigram further suggests to the students an intimate relationship to a history that may not necessarily be their own and reinforces the idea that this history can be understood and experienced simply by walking.

The order of the readings roughly follows the learner's process of becoming familiar with her new environment. An early reading assignment, for example, is Edward Said's essay "Reflections on Exile," which emphasizes the significance of leaving the familiar territory of home. Although not exiles per se, the learners are asked to look both backwards and forwards, thinking about what constitutes home and their emplacement within it. Said provides an invaluable framework for thinking about the sociopolitical as well as emotional mechanisms of belonging to a place and a people. Most significantly, Said suggests that there are lessons to be learned from exile which again can be extended to learners, despite their voluntary displacement. The exile learns to "see the entire world as a foreign land." (Said, 2002, p.186) This juxtaposition of creates a plurality of vision, which, in its simultaneous awareness of habits, places, and cultures diminishes orthodox judgment and elevates appreciative sympathy/compassion for the unfamiliar or new.

Subsequent readings in the course focus almost exclusively on the city and emphasize walking. Particularly when read together, Guy Debord's essay Introduction to a Critique of Urban Geography and excerpts from Michel de Certeau's The Practice of Everyday Life suggest practical strategies for reading the city as a social space. Debord proposes and describes a number of useful terms, including dérive and psychogeography. Dérive is a Situationist game, whereby

... one or more persons during a certain period drop their relations, their work and leisure activities, and all their other usual motives for movement and action, and let themselves be drawn by the attraction of the terrain and the encounters they find there. Chance is a less important factor in this activity than one might think: from the dérive point of view cities have psychogeographic contours, with constant currents, fixed points and vortexes . . . (Debord 1958/2008) 
Beginning from the premise that the walks are a kind of dérive, learners are encouraged to view city space using the principles of psychogeography, a technique which emphasizes the individual position of the observer, and privileges intuitive readings of the ambiance of a place, but without relying on traditional aesthetic readings or the usual interpretative signs, such as architectural styles, décor, and housing conditions. What Debord proposes instead is a series of intentional misreadings and imaginative leaps. For instance, one might wander through Harz, Germany while following a map of the London underground, or one could imagine all the equestrian statues of the whole world accumulated in a desert as a monument to the great massacres of history (Debord 2, p. 1).

De Certeau similarly disrupts the expected methodology for interacting with city space. Extending the metaphor of city as text, de Certeau suggests rhetorical operations as walking practices. One such operation is the asyndeton - a collecting of fragmentary images that seeks to eliminate a consecutive reading of the city fabric and "open gaps in the spatial continuum" (de Certeau, 1988, p. 101). For de Certeau, these gaps or ruptures are critical to emplacement, that is, being somewhere instead of nowhere. They also facilitate an understanding of experience that extends beyond the "technological system of a coherent and totalizing space that is linked and simultaneous" (de Certeau, p. 102). The narratives that result from experiencing such fragmentary images are based on the idiosyncratic, the local, the subjective as opposed to the mythical, the homogenous, the corporate. De Certeau further links this approach to reading the city to the history of map making. Before the panoptic map as we know it, there was the itinerary, essentially a list of landmarks, distances, points of interest primarily for travelers on foot. The map here represents the static totalizing of space, while a revised idea of the itinerary can be used as a practical tool for representing some of the rhetorical operations suggested above (de Certeau, pp. 120-121).

As the semester progresses the students are encouraged to consider the political stakes involved in walking and the kinds of investigation discussed here. The readings, moreover, reflect this shift. Texts such as Michel Foucault's Of Other Spaces and Frederic Jameson's Postmodernism, or, the Cultural Logic of Late Capitalism employ a methodology of reading familiar to the students from previous texts. These include mapping, walking, the instructive nature of memory and so on. Jameson in particular suggests that 
as late capitalist subjects, our understanding of history has become spatial rather than temporal. The new kind of alienation we encounter in the postmodern metropolis thus acquires a heightened sense of political urgency. Although Athens is not in the strict sense a postmodern metropolis in the way that certain American city centers are, (having erased every trace of their previous life), learners easily imagine postmodern space by recalling their own experiences of other urban areas. The tools for disalienation that Jameson suggests, among others the compiling of cognitive maps, bear a striking resemblance to de Certeau's methodology. Putting into practice the critical propositions of the texts, student learners begin to understand how urban spaces provide a scaled down model of their own relationship to dominant ideology, and, emphasizing the subjective, a way to think their own experience.

Foucault, in Of Other Spaces, provides an important counterpoint to the methodologies and strategies of emplacement suggested by Jameson. In contrast to Jameson he suggests that space, as a dominant theoretical model, is not our epoch's innovation and that, historically speaking, emplacement also implied a strict social hierarchy (Foucault, 1986, p. 22). In response to the fluidity of our epoch, in which space is more a "network of connecting points" (Foucault, 1986, p. 23), Foucault coins the invaluable term heterotopia. Heterotopias are "[sites] that have the curious property of being in relation with all other sites, but in such a way as to suspect, neutralize, or invert the set of relations that they happen to designate" (Foucault, 1986, p. 24). The text provides an opportunity for learners to return to the idea of how space is socially coded and to reconsider their own emplacement in such public sites, the way they navigate urban space, and how these kinds of decodings can provide tools for understanding more abstract concepts such as their own relationship to history and ideology.

Finally, Walter Benjamin's Arcades Project and One Way Street provide both a practical model for the "fragmentary spatial stories" we ask learners to compile, as well as a highly insightful description of the city, in this case $19^{\text {th }}$ century Paris. It is noteworthy that the section on the Flâneur does not seek to define the flâneur, but rather reads as the notes of a practicing flâneur, and in this it is particularly interesting that Benjamin is not describing his own time. Nevertheless, the section teems with images of crowds, street vendors, and architecture, reads as if the city were one's private space, with the arcade one's drawing room. This process of making familiar or making intimate is the learning objective of the readings. 
The Greek Key walks operate as field classes with a number of immediate outcomes. By traveling on their own to the walk's set meeting point, students learn to navigate the city in limited time. As well, they come to better understand how public transportation works and are able to observe the behavior of commuters during peak morning hours. When local facilitators share historical knowledge, personal memories, and collective urban myths about a site's background, the foreign environment quickly acquires the tactility and familiarity of the everyday. Further, an insistence on observation of minute details of social life and the built environment, combined with the facilitator's narrations, teaches students to learn the unfamiliar by walking, looking, and sensing. This learning methodology helps students step faster out of the shock and awe of seeing a foreign land to truly engage with urban space and everything inside it.

Observations and questions during Greek Key walks create a fertile ground for group discussion; seeing something with fresh eyes welcomes insights, comparisons, and proposals about issues that often seem ordinary and insignificant to natives but may be strangely impressive to non-natives. Discussions during the walks cover a variety of often overlapping disciplines, supplemented with personal anecdotes from home and other occurrences in Greece. Through these various forms of interpretation learners begin to make sense of the space around them and to bring together once disparate images to form a more cohesive picture of the real Athens. In the short space of the semester and their residence in Athens, the students have become learned walkers, both sagacious and integrated, escaping the status of wandering tourist.

"Always keep Ithaka in your mind. / Arriving there is your destination. / But don't hurry the journey at all. / Better if it lasts many years, / and your moor on the island when you are old, / rich with all you have gained along the way, / not expecting Ithaka to make you rich. / Ithaka gave you the beautiful journey. / Without her you would not have set out on your way. / She has no more to give you. / And if you find her poor, Ithaka did not betray you. / With all your wisdom, all your experience, / you understand by now what Ithakas mean." (Cavafy, 2006, Ithaka, pp. 48-49. A. Barnstone, Transl.)

A crucial goal of the Greek Key learning process is to enable students to reflect on their cultural experiences. With the guided walks, this is facilitated 
by the posting of brief responses to the walks on the Arcadia Center's website within 24 hours. Learners are encouraged to post in the affective rather than academic voice to allow for the spontaneous expression of feelings and reactions to the walks. In short texts, learners note their individual impressions, pick a recurring theme that particularly stood out for them, comment on how the walk expanded their apprehension of Athenian culture beyond their initial expectations, and compare this to familiar analogies of urban living. For many students, Athens is the first city environment in which they have resided, even temporarily. Their reflections therefore become referential not just to Greek urbanity but city life in general.

An alternative to written responses is the composition of a visual haiku. This is a sequence of three images relating to a learner's observations during a walk, images that have some poetic relationship to each other. The images are posted on the website and followed by a brief written description. The visual haiku enhances photographic skills to extract and synthesize a narration descriptive of the city in ways other than writing. Its poetic structure allows for spatial qualities to surface as contrasting or complementary and welcomes an open-ended interpretation of their cultural meanings.

Following each group's second Greek Key walk, responses take the form of a photomontage. Juxtaposing real landscapes with photographic fragments from another context, learners use their imaginations to invent a mediated version of existing sites with a twist of desire and humor. Examples include unexpected distortions of an Akropolis postcard (under the title Acropoblis), a statue of Ronald McDonald on the stone seating of an ancient shrine, and misplaced street vendors in the serene surroundings of the Parthenon. The collaged images, either digital or handcrafted, become an opportunity to produce irrational alternatives of city sites beyond social norms and political correctness, while hinting at some of the stereotypes that the learners themselves hold on to. Further, the photomontage assignment encourages a critical stance toward representations of the city in contemporary media and activates the possibility of individual appropriation not just of public space, but of its image.

Throughout the semester students find themselves experiencing new and sometimes shocking occurrences. Like a Virgin posts to the Arcadia website help bring these newfound and often awkward moments to light. Varying from inadvertent hand gestures to riding in the wrong direction on the metro, most of the occurrences involve person-to-person experience, often addled by a language barrier. The posts allow learners to relate the confusion and torment 
that comes in navigating a new place, while acquiring useful insight into the nuances of Greek society.

Use of the affective voice in reflective responses and the emphasis on observation present the Greek Key facilitators with several pedagogical challenges. Most of the students have been raised in a learning environment that is teacher driven, stresses the acquisition of knowledge and a body of specific facts, and evaluates learners' abilities to discuss and share knowledge and facts using an academic voice. It is therefore not unusual that student learners question the validity of the Greek Key and even consider it slightly facile because it places significance on personal observation and description of that observation in affective language.

The facilitators therefore stress three questions in advance of each walk:

1. of the method, e.g. observation - what can describe to you who lives here and for what purpose they use this space?

2. of a reading - what strategy is the author suggesting for reading the city?

3. of the space - can you sense an ambiance here and/or can you identify this landscape's memory?

Greek Key facilitators employ a non-authoritative voice to help learners gain confidence to voice personal opinion when making cultural observations or reading dense discursive text. This makes it less difficult to teach that the physical experience of walking combined with careful observation of the environment can result in a satisfying, exciting and mind-opening process that makes the world become familiar. By the third of four group walks, many of the learners have begun to recognize and acknowledge the ways they read the city. Informed as well about of the city's development, the learners come to question their own assumptions as well as use their firsthand experience to distance themselves from the authority of a textbook's propositions.

Complementing the four group walks, each completes three separate Athoriginal Walk exercises, each of which requires the student to venture out alone, unassisted by a facilitator or host national. Twice, learners choose from a variety of seven walking options to complete the assignment; for the third walk, they invent their own route. Keeping to the notion of experimentation and surprise, no extra research is necessary prior to going on the walks. Students may travel to suburban areas to compare them, find out about ethnic 
minorities or religious traditions which flourished in the past (Jewish community, the mosques of the Ottoman occupation), or experience firsthand the Athenian leisure and arts scene in venues selected specifically for their atmosphere, unusual location and exhibits, etc. One suggested Athoriginal Walk sends student sojourners to two diametrically opposed neighborhoods. Suburban Egaleo has long been a working-class stronghold, evidenced by its densely packed row homes and modest cafes. There is however a stretch of land around the metro stop which has seen some recent growth, begging the question of capitalist expansionism and urban gentrification bleeding into residential living space. On the other hand, Kifissia has traditionally been an aristocratic Athenian suburb and has recently expanded into a popular shopping and leisure district. Chic cafes and glibly designed brand-name boutiques mark a radical departure from Egaleo; Kifissia's shops, people, and attitudes present a capitalist Elysium where the exchange of money is the main form of discourse.

Students reflect on their experiences in writing, illustrating their assignments with photographs, proof of transportation tickets and so on. Traveling to the destinations unaccompanied and learning the local culture through immediate interaction and reflection renders learners actively participating in the culture but simultaneously distanced from it; sharing an intimacy with the native environment yet critically aware of its operative structure and traditions. Moreover, during Athoriginal Walks, learners wander into areas away from their familiar downtown, are informed about Greek social history, and witness the ways it is depicted in institutional collections (museums) or mediated in contemporary art (galleries). Most significantly, learners are further able to experience the stratifications of collective memory and modern class struggle as these are made visible in the streetscape and sensed in the interior of public venues.

The spatial narrative assignment is designed to augment the use of maps merely for geographical identification. Using the traditional printed map as a starting point, students are asked to reflect on the printed map's inherent ability to homogenize cultural space and eliminate both political notions of spatial (im)permeability and the customary distinction of public and private in the real sites it depicts. Learners are called to recognize the map as a communicative tool and trace its origins in traditional traveling or pilgrimage accounts. The spatial narrative aims at identifying how public sites are reshaped and transformed in one's mind to trace the conscious or subconscious mental maps each one of us uses to navigate. It engages students with the 
workings of memory in selecting, omitting, multiplying, and rescaling personal experience and asks them to compose informative yet affective depictions of the places they have visited. Students are allowed to choose the form their spatial narratives will take, with the only restraint a stipulation that that the narrative cannot be a traditional academic text. Given the ephemeral quality of experiencing the outside world, artistic media are encouraged, including sketches from memory, collages, poems, and video.

At the conclusion of the semester, this question begs to be answered: "How has the Athens you know now differ from your expectations of Athens prior to, and even at, arrival?" As learned walkers, students are able to dig past all the attractive and sensational sites for which Greece is so well known. What is the true identity of Athens and an Athenian? Beyond the obvious intrigue of prominent contradictions inherent in any place where the historic and the modern world collide, it is the inclination of Athens to westernize and foster a sense of permanence rendered by yellowed marble and McDonald's' golden arches that is perhaps the most striking. Just as the city itself is a hybrid of old and new, students are asked to write an essay elucidating their expectations and how they were evidenced or disproved. While earlier projects in the Greek Key Seminar required students to reflect on their memories of other urban spaces and cultural happenings, the Double Exposure challenge is designed to confront and articulate the differences in belief and experience. (Halkias, 2004, p.19) Through extracting such responses learners re-trace the Greek capital as an inclusive cultural environment, composing the patchwork that is modern Athens.

By the end of the course, learners have gained more than just an in-depth knowledge of their host city. They now have an ability to read and understand any environment. This urban literacy is essential to any traveler, and will prove useful in both intimate and unfamiliar settings. Ultimately the goal of the Greek Key is to teach new ways of perceiving a place by utilizing observation and revealing ways to represent the ephemeral experience of urban life. The evolution in thought regarding the proper representation of a city is the most difficult to impart. Thus, students are encouraged to observe actively a space by interacting with it; in turn, experience is, and only ever can be, a subjective reading of one's surroundings. The map - a vain attempt at reconstructing a city with flat lines for streets and green shadows for parks is a useful device that remains sterile, ignorant of any emplaced cultural meaning. The Greek Key allows a learner's personal outlook to intermingle 
with the social atmosphere of an alien place, while emphasizing first-hand experience and interaction as a way of critically reading culture and place.

The experience of cultural difference inevitably causes students to reconsider their own belonging to a particular identity and puts to practice their abilities and limitations of adaptation in their temporary new home. The course's insistence on first-hand exploration, observation and reflection engages learners not only with the unfamiliar culture of Athens, but foremost with the learner's own mechanisms of dealing with the foreign. The Greek Key: Experiencing Athens as a Cultural Landscape provides a platform for learners to voice their immediate reactions and respond to recent moments of cultural otherness in light of previous expectations. The subjective readings discussed during the course challenge learners to articulate, place in perspective, discuss, and criticize their very own cultural idiosyncrasies, encouraging introspection. The landscapes, cultures and environments of Athens assist the student learners in the processes of getting acquainted with themselves.

\section{Note}

In its original form, The Greek Key: Experiencing Athens as a Cultural Landscape is the creation of Jan Sanders and Eirene Efstathiou. Maria Michou added her particular skills to the team of facilitators in 2009. Before arriving to study in Athens at the Arcadia Center for Hellenic, Mediterranean and Balkan Studies in the fall semester of 2009, Hunter Augeri, a student at the University of the Arts in Philadelphia, proposed an independent project which mirrored the Greek Key in some fundamental ways. Working throughout the fall of 2009 with Efstathiou and Michou, Augeri studied the city of Athens via the perspective of walking. The recreation of his experiences in film at once articulated the fragmentary visual and sensory memories of the pedestrian and the contradictory responses of the traveler and resonate with the atmospheric psycho-geographies that narrate both Athens' hedonistic and haunting faces. As a co-author, Augeri has contributed a student voice and viewpoint to this article.

\section{References}

Benjamin, W. 1999. The Arcades Project. (H. Eiland \& K. McLuaghlin, Transl.). Cambridge, MA: Harvard University Press.

Benjamin, W. (2009). One-Way Street and Other Writings. (. J. A. Underwood, Transl.). Penguin Modern Classics. 
Calvino, I. (1997). Invisible cities. (W. Weaver, Transl.).. London: Vintage Classics.

Cavafy, C. P. (2006). The collected poems of C.P. Cavafy. A new translation, (Barnstone, A. Transl.) New York and London: W.W. Norton \& Company. de Certeau, M. (1988). The practice of everyday life. Berkeley and Los Angeles: University of California Press.

Debord, G-E. (1958). Theory of the Dérive. Internationale Situationniste \# 2. Retrieved November 15, 2008 from http://library.nothingness.org/ articles/SI/en/display/314.

Foucault, M. \& Miskowiec, J. (1986) Of other spaces. Diacritics, 16 (1) Spring, 22-27. Baltimore, MD: The John Hopkins University Press.

Halkias, A. (2004). The empty cradle of democracy: Sex, abortion, and nationalism in modern Greece. Durham and London: Duke University Press.

Jameson, F. (1991). Postmodernism, or the cultural logic of late capitalism. Duke University Press.

Pallasmaa, J. (2005). The eyes of the skin: Architecture and the senses. Chichester: Wiley-Academy.

Said, E. (2002).Reflections on exile. in E. Said,. Reflections on exile and other essays (pp.173-186). Cambridge, MA: Harvard University Press. 